\title{
O DIÁLOGO NA EDUCAÇÃO INFANTIL: 0 MOVIMENTO, A INTERDISCIPLINARIDADE E A EDUCAÇÃO FÍSICA
}

\author{
EL DIALOGO EN LA EDUCACIÓN INFANTIL: EL MOVIMIENTO, LA \\ INTERDISCIPLINARIDAD Y LA EDUCACIÓN FÍSICA
}

DIALOGUE IN PRESCHOOL: MOVEMENT, INTERDISCIPLINARITY, AND

PHYSICAL EDUCATION

Daniela Bento Soares*, Elaine Prodócimo*, Ademir De Marco*

Palavras-chave Movimento.

Educação Física.

Pré-escolar.

Educação.

\begin{abstract}
Resumo: Considerando documentos que foram referência para a Educação Infantil (EI), como o Referencial Curricular Nacional para a Educação Infantil (RCNEI) (BRASIL, 1998), que inclui o eixo Movimento, e as Diretrizes Curriculares Nacionais para a Educação Infantil (DCNEI) (2010), que especificam as interações e as brincadeiras para crianças pequenas na $\mathrm{El}, \mathrm{o}$ objetivo deste artigo foi investigar a presença do movimento na rotina e suas interseções com as demais experiências em atividades realizadas em uma creche de um município do interior de São Paulo. As observações indicaram que propostas interdisciplinares são possíveis, e estão presentes no cotidiano das escolas de El, apesar de o movimento como finalidade não ser frequentemente incentivado nas experiências diárias das crianças.
\end{abstract}

Palabras clave Movimiento. Educación Física. Preescolar. Educación.

Keywords Movement. Physical Education. Child, preschool. Education.
Resumen: Considerando documentos que fueron referencia para la Educación Infantil (EI), como el Referencial Curricular Nacional para la Educación Infantil (RCNEI) (Brasil, 1998), que incluye el eje Movimiento, y la Directrices Curriculares Nacionales para la Educación Infantil (DCNEI) (2010), que especifican las interacciones y los juegos para niños pequeños en la El, el objetivo de este artículo fue investigar la presencia del movimiento en la rutina y sus intersecciones con las demás experiencias en actividades realizadas en un jardín infantil de un municipio del interior de São Paulo. Las observaciones indicaron que propuestas interdisciplinarias son posibles y están presentes en la vida cotidiana de las escuelas de El, aunque el movimiento como propósito no sea estimulado de manera frecuente en las experiencias diarias de los niños.

Abstract: This study considers the documents that served as references for preschool as the so-called Nacional Curricular Reference for Preschool (RCNEI) (BRASIL, 1998), which include the axis Movement, and the Nacional Curricular Guidelines for Preschool (DCNEI) (BRASIL, 2010). The latter specify interactions and games for young children in preschool. The article investigates the presence of movement in school routine and its relation with other experiences in activities conducted in a preschool located in a city in the state of São Paulo. Observations indicated that interdisciplinary proposals are possible and are present in preschool routines, although movement as an end is not often encouraged in children's daily experiences.
* Universidade Estadual de Campinas. Campinas, SP, Brasil. E-mail: danibsoares@hotmail.com

Recebido em: 04-08-2015 Aprovado em: 13-09-2016 (c) (1) (8) Licence 


\section{INTRODUÇÃO}

O movimento é uma forma de linguagem que proporciona autonomia para a criança, pois se compõe de expressão e intenção. Durante as atividades, as crianças exploram interações sociais e o meio ambiente, conhecem espaços, entendem conceitos, estabelecem relações entre objetos e acompanham ritmos e músicas, ações que se concretizam por meio do brincar. Portanto, como o movimento é parte constitutiva da brincadeira de crianças pequenas, ele deve ser parte integrante do currículo na educação básica (BRASIL, 2010), permitindo a construção de conceitos e valores.

É necessário buscar uma concepção de escola para a criança pequena que valorize essa linguagem e sua articulação com os demais componentes do currículo da Educação Infantil (EI) (FALKENBACH; DREXSLER; WERLE, 2006; GARANHANI, 2002). É possível tornar o movimento tema aglutinador para os conhecimentos explorados na El, propiciando propostas interdisciplinares que se coadunam com os interesses das crianças pequenas, ao mesmo tempo em que se evita a disciplinarização (CERISARA, 1999; SAYÃO, 2002a).

O Referencial Curricular Nacional para a Educação Infantil (BRASIL, 1998), o RCNEI, propõe que a dimensão Conhecimento de Mundo seja desenvolvida associando os eixos: Movimento, Música, Artes Visuais, Linguagem Oral e Escrita, Natureza e Sociedade e Matemática. O Movimento é o primeiro eixo a ser discutido no documento, pois potencializa o despertar e a aquisição de outros conhecimentos, mediados pela expressão corporal da criança. Neste sentido, é visto como linguagem própria das crianças pequenas, embora seja incentivado também como objetivo final de experiências, reforça as descobertas motoras e as expressões corporais. Com base nesse princípio, De Marco (2012), alinhado às proposições teóricas recentes, que lançam luzes sobre as contribuições da Educação Física (EF) ao desenvolvimento global da criança, apresenta o modelo interdisciplinar retratado na Figura 1.

Figura 1 - Modelo interdisciplinar na El

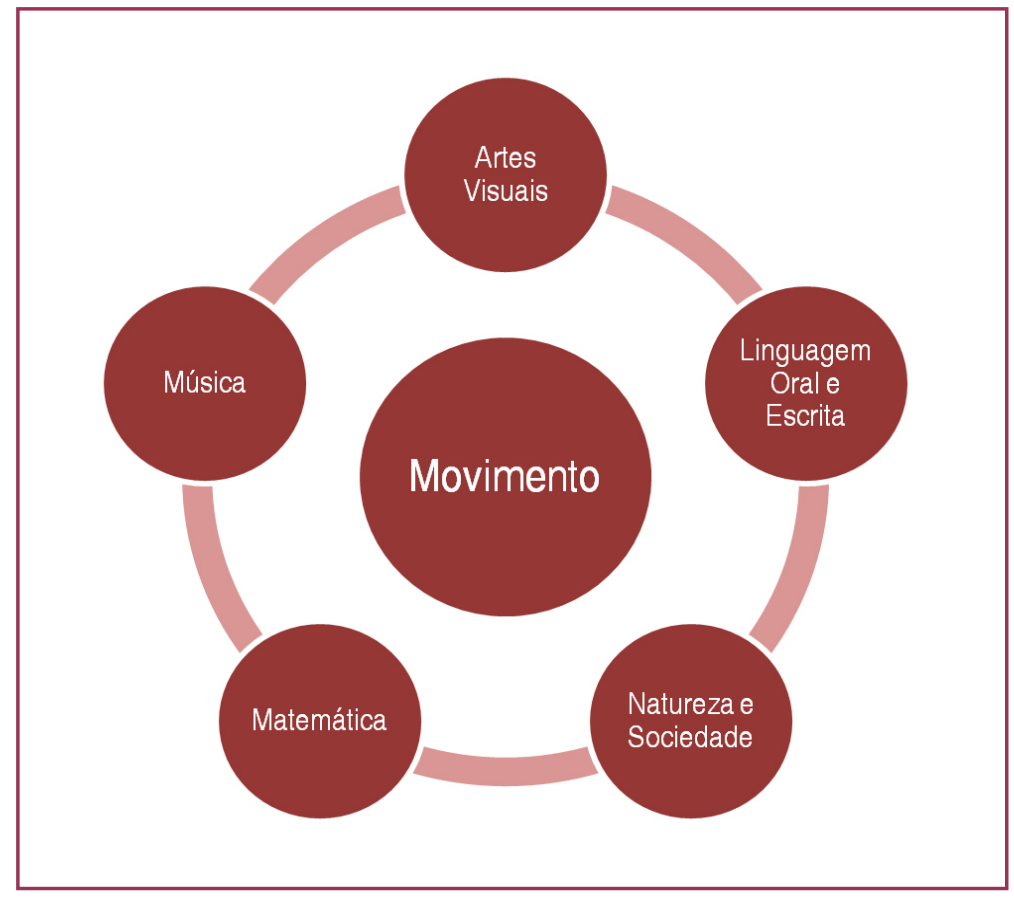

Fonte: De Marco (2012, p. 90) 
Posteriormente ao RCNEI (BRASIL, 1998), foram divulgadas as Diretrizes Curriculares Nacionais para a Educação Infantil (BRASIL, 2010), DCNEI, outro importante documento para nortear a El, que explicita os objetivos e os procedimentos que devem organizar o currículo a fim de proporcionar experiências para as diversas linguagens da criança pequena, como a verbal, gestual, visual e musical. Com a promulgação desse novo documento, o RCNEI (BRASIL, 1998) tornou-se um tratado histórico, mas mantém sua importância na discussão das estratégias pedagógicas a serem realizadas na El.

Assim, o objetivo deste artigo é investigar a presença do Movimento e seu papel como elemento articulador das diversas experiências na El ligadas aos eixos da dimensão Conhecimento de Mundo, propostos pelo RCNEI (BRASIL, 1998). Com esse intuito, foi realizado um levantamento em atividades de uma creche numa cidade do interior do estado de São Paulo.

\section{BASES TEÓRICAS}

O movimento, a linguagem desde a mais tenra idade, é a forma de expressão mais utilizada na infância. Ele se caracteriza como um sistema complexo de significação e comunicação, verbal e não verbal, baseado no emprego de imagens, sons e gestos (PALOMO, 2001).

Basei (2008, p. 5) afirma que "o corpo fala, cria e aprende com o movimento, expressando-se através de gestos, ricos de sentido e de intencionalidades". Para Garanhani (2002, p.109), o movimento constitui a matriz básica da aprendizagem, afinal, "a criança transforma em símbolo aquilo que pode experimentar corporalmente, e seu pensamento se constrói, primeiramente, sob a forma de ação". Ela necessita movimentar-se para conhecer e compreender os significados presentes no seu meio.

Citando Guirra e Prodócimo (2010, p. 712):

O trabalho corporal deve ser uma tônica coletiva, pois acreditamos que na El tudo se dá de forma indissociável, principalmente, porque o corpo traz consigo características e significações sociais próprias, que não podem ser arrancadas dos alunos e desprezadas, porque, culturalmente, fazem parte de sua história e de sua sociedade.

A característica curricular não disciplinarizadora da El, a grande importância do movimento como linguagem da criança pequena e canal de descoberta de novos conhecimentos e a variedade de profissionais envolvidos tornam a escola da criança pequena um ambiente interdisciplinar.

O conceito de interdisciplinaridade surgiu na segunda metade do século passado, em resposta à necessidade das Ciências Humanas e da Educação de superar a fragmentação e o caráter da especialização do conhecimento, causados pela epistemologia de tendência positivista (THIESEN, 2008). Baseando-se em tempos remotos, procura-se resgatar 0 conhecimento como um saber de totalidade. Gattás e Furegato (2006) lembram o ideal grego de Paideia, para exemplificar que o conjunto de todos os saberes reunia diferentes áreas ou disciplinas, articuladas entre si.

A interdisciplinaridade define-se como qualquer forma de combinação entre duas ou mais disciplinas (ou conhecimentos que foram segmentados). Objetiva a compreensão de um 
objeto a partir da confluência de pontos de vista e elabora síntese sobre determinado assunto. Assim, promove a superação da visão parcelar de mundo e resgata a centralidade do homem, implicando reorganização do processo de ensino-aprendizagem e supondo cooperação dos profissionais envolvidos (GUIMARÃES, POMBO, LEVY, 1994). Muitas concepções visam favorecer o religamento das fronteiras entre as disciplinas, permitindo que o conhecimento seja mais harmonioso (JAPIASSU, 1976). A interdisciplinaridade facilita o planejamento do currículo e o trabalho em equipe, caso este esteja aberto ao diálogo, à comunicação e às novas propostas (NEDEL, 2010).

Dessa forma, entende-se que o movimento da criança pequena é um elemento aglutinador para o qual o conhecimento possa ser explorado de maneira interdisciplinar, uma vez que é a forma de realização de experiências e de comunicação com o mundo. 0 conhecimento abordado interdisciplinarmente se traduz em brincadeiras, realizadas a partir do movimento, que introduzem conceitos e valores (BRASIL, 1998; BRASIL, 2010). Formase, então, um ciclo, no qual interdisciplinaridade-movimento-conhecimento-experiências são associados na atividade da criança pequena.

\section{MÉTODO}

Este estudo, de natureza exploratória, consistiu numa pesquisa de campo, aprovada pelo Comitê de Ética em Pesquisa da Faculdade de Ciências Médicas da UNICAMP, sob o protocolo 338.175, de 29 de julho de 2013.

Participaram desta pesquisa as educadoras (professoras e agentes de educação) da CEMEI/EMEI investigada $(n=29)$, a direção e a coordenação da escola $(n=4)$, as crianças autorizadas ( $n=149$ ) e suas famílias. Esta organização compreende o Agrupamento I (AG I), que reúne crianças de 4 meses a 1 ano e 6 meses, e o Agrupamento II (AG II), com crianças de 1 ano e 6 meses a 3 anos. Estas salas são denominadas AG I A e B, AG \| A, B, C e D. Essas turmas, com exceção do AG II C, incluída apenas a segunda etapa da pesquisa, resultaram em uma média de 31,8 crianças por grupo.

Todas as turmas contam com professora no período da manhã e três (AG I) ou duas (AG II) agentes de educação, que se revezam nos períodos matutino e vespertino. A relação entre o número de crianças e educadoras configurou a média de 9,2 para o período matutino e de 12,8 para o período vespertino.

A observação da rotina das salas foi realizada em outubro de 2012 por nove membros do Grupo de Estudos em Educação Física no Desenvolvimento Infantil (GEEFIDI), os quais adquiriram experiência nessa tarefa com participação ativa nas pesquisas do grupo. Cada observador permaneceu durante um período da rotina diária em uma das salas. Para tanto, foi utilizado o Roteiro de Observação da Rotina, denominado ROTIN, elaborado pelos integrantes do GEEFIDI. Ele apresenta questões de múltipla escolha e perguntas dissertativas sobre aspectos como: relações interpessoais, ocupação espacial da escola e condições dos locais utilizados, tipos de atividades livres e dirigidas e duração em cada etapa do dia.

A observação de atividades dirigidas propostas pelas educadoras com foco no Movimento ocorreu entre maio e junho de 2013 e foi realizada por dois membros do GEEFIDI. 
o Roteiro de Observação de Atividades Práticas, ROBSERV, criado pelo GEEFIDI, foi utilizado, enfocando descrição e organização das atividades direcionadas.

Foi realizada a observação maciça em equipe, na qual a rede de observadores distribuiu-se pela amostra, identificando os mesmos aspectos (LAKATOS; MARCONI, 2003).

Os dados obtidos foram analisados quantitativamente, sendo apresentados em tabelas. Paralelamente, os dados observacionais qualitativos foram categorizados e analisados a partir de quadros.

\section{RESULTADOS E ANÁLISES}

São apresentados os resultados obtidos para a descrição da rotina pelo instrumento ROTIN, desde o momento inicial de entrada (7h) até o período de saída (11h40 e $12 \mathrm{~h} 30$ para os alunos de meio período e $17 \mathrm{~h}$ para os demais alunos).

Tabela 1 - Distribuição temporal das atividades diárias das salas observadas (em minutos)

\begin{tabular}{ccccccc}
\hline & AG I A & AG I B & AG II A & AG II B & AG II C & AG II D \\
\hline Acolhimento & 60 & 75 & 60 & 70 & 65 & 55 \\
Café da manhã & 30 & 15 & 30 & 15 & 25 & 20 \\
Atividade manhã & 30 & 40 & 45 & 65 & 60 & 130 \\
Lanche manhã & 30 & - & - & - & - & - \\
Troca de fraldas & 40 & 55 & 55 & - & - & - \\
Almoço & 30 & 25 & 30 & 30 & 40 & 30 \\
Sono & 200 & 205 & 170 & 140 & 140 & 160 \\
Lanche tarde & 40 & 25 & 15 & - & 20 & - \\
Troca de fraldas & - & - & 30 & - & - & - \\
Atividade intermediária & 40 & 15 & 45 & 75 & 70 & 80 \\
Atividade tarde & 40 & - & - & - & - & 20 \\
Banho completo & - & 50 & - & - & - & - \\
Janta & 15 & 20 & 30 & 30 & 15 & 20 \\
Espera para saída & 105 & 90 & 75 & 90 & 110 & 90 \\
\hline
\end{tabular}

Fonte: Autoria própria.

Nos dados da Tabela 2, observa-se que o período de acolhimento é semelhante em todas as turmas, enquanto as demais atividades perduraram por um tempo proporcional à idade das crianças, ou seja, quanto menores as crianças, mais tempo destinado às atividades de cuidar. Esses dados estão em concordância com o retratado por Falkenbach, Drexsler e Werle (2006), que indicam que existem escolas que apresentam cronogramas diários em que são determinados horários de refeições e atividades em sala ou pátio, mas que não indicam um horário específico para o desenvolvimento de aspectos especificamente relacionados ao Movimento. Essa dinâmica, ao mesmo tempo em que facilita a distribuição dos trabalhos corporais durante a semana, não regulariza ou exige sua realização, ficando para a equipe pedagógica a decisão por seu oferecimento. 
Tabela $2^{1}$ - Distribuição temporal entre as atividades (em minutos)

\begin{tabular}{ccccccc}
\hline & AG | A & AG I B & AG \| A & AG \| B & AG II C & AG II D \\
\hline Alimentação & 145 & 85 & 105 & 75 & 100 & 70 \\
Higiene & 40 & 105 & 85 & 0 & 0 & 0 \\
Atividades & 275 & 220 & 225 & 300 & 305 & 375 \\
Sono & 200 & 205 & 170 & 185 & 140 & 160 \\
\hline
\end{tabular}

Fonte: Autoria própria.

Os dados da Tabela 3 demonstram o tempo dedicado para ações que educam, brincam e cuidam (BRASIL, 1998). Quanto mais avançada a idade das crianças, maior é o tempo reservado para as atividades educativas que não envolvem alimentação, higiene e sono. 0 motivo é claro: crianças menores requerem maiores cuidados. Embora o movimento esteja presente e seja considerado essencial nas ações de higiene e também nas de alimentação, é no brincar que são exploradas as práticas corporais infantis (GARANHANI, 2002).

O Quadro 1 apresenta as tarefas observadas durante o período de atividades e suas distinções entre serem dirigidas ou não. Atividades direcionadas e não direcionadas são aconselhadas pelas DCNEI (BRASIL, 2010), a fim de que os professores garantam a integração de diversas áreas do conhecimento e promovam a constituição de conhecimentos e valores. Logo, reforça-se que a interdisciplinaridade é uma prática recomendada pelos documentos norteadores da El no Brasil e pela literatura.

Quadro 1 - Atividades observadas durante os momentos pedagógicos.

\begin{tabular}{|c|c|c|c|c|c|c|}
\hline \multirow[t]{2}{*}{ Turma } & \multirow{2}{*}{$\begin{array}{l}\text { Tipo de } \\
\text { Atividade }\end{array}$} & \multicolumn{5}{|c|}{ Momento da Rotina } \\
\hline & & Acolhimento & Manhã & Intermediário & Tarde & Saída \\
\hline \multirow{2}{*}{$A G \mid A$} & $\mathrm{D}$ & - & $\begin{array}{l}\text { Brinquedos } \\
\text { recicláveis }\end{array}$ & - & - & - \\
\hline & ND & Brinquedos & - & Parque & $\begin{array}{c}\text { Parque e } \\
\text { brinquedos }\end{array}$ & Brinquedos \\
\hline \multirow[t]{2}{*}{$A G \mid B$} & $\mathrm{D}$ & $\begin{array}{l}\text { Músicas com } \\
\text { fantoches }\end{array}$ & - & - & - & - \\
\hline & ND & Brinquedos & Bola e parque & Parque & Brinquedos & Brinquedos \\
\hline \multirow[t]{2}{*}{$\begin{array}{l}\text { AG } \\
\| A\end{array}$} & $\mathrm{D}$ & $\begin{array}{c}\text { Contação de } \\
\text { histórias e } \\
\text { músicas }\end{array}$ & $\begin{array}{c}\text { Músicas com } \\
\text { acompanhamento } \\
\text { de instrumentos } \\
\text { musicais }\end{array}$ & - & - & - \\
\hline & ND & Brinquedos & Parque e filme & Pátio & - & Brinquedos \\
\hline \multirow[t]{2}{*}{$\begin{array}{l}A G \\
\| B\end{array}$} & $\mathrm{D}$ & - & $\begin{array}{l}\text { Músicas com } \\
\text { instrumentos; } \\
\text { contação de } \\
\text { histórias }\end{array}$ & - & - & - \\
\hline & ND & $\begin{array}{c}\text { Brinquedos e } \\
\text { massinha }\end{array}$ & Pátio & Parque & - & Filme \\
\hline \multirow[t]{2}{*}{$\begin{array}{l}\text { AG } \\
\| C\end{array}$} & $\mathrm{D}$ & - & $\begin{array}{c}\text { Músicas e contação } \\
\text { de histórias }\end{array}$ & $\begin{array}{l}\text { Contação de } \\
\text { histórias; desenho } \\
\text { relacionado com a } \\
\text { história; brinquedos } \\
\text { de encaixe e blocos }\end{array}$ & - & - \\
\hline & ND & Brinquedos & Parque & - & - & Filme \\
\hline
\end{tabular}




\section{Continuação do quadro $1 \ldots$}

\begin{tabular}{|c|c|c|c|c|c|c|}
\hline \multirow{2}{*}{$\begin{array}{c}\text { AG } \\
\text { II D }\end{array}$} & D & - & $\begin{array}{c}\text { Músicas; atividade } \\
\text { de letramento; } \\
\text { brincadeira com } \\
\text { música e números; } \\
\text { atividade de pintura }\end{array}$ & $\begin{array}{c}\text { Brincadeiras com } \\
\text { bola }\end{array}$ & $\begin{array}{c}\text { Brincadeiras } \\
\text { com música } \\
\text { com a } \\
\text { habilidade de } \\
\text { rastejar }\end{array}$ & - \\
\cline { 2 - 6 } & ND & Brinquedos & Filme & - & - & $\begin{array}{c}\text { Filme e } \\
\text { brinquedos }\end{array}$ \\
\hline
\end{tabular}

Legenda: D - dirigida; ND - não dirigida.

Fonte: Autoria própria.

A rotina da escola é positiva para o trabalho interdisciplinar, pois permite que o movimento seja explorado de forma específica ou como linguagem da criança (GARANHANI, 2002), favorecendo, assim, a não disciplinarização (SAYÃO, 2002a). De modo geral, as atividades dirigidas relacionavam-se com experiências musicais. Sendo a El um espaço para a promoção da cultura da criança, é plausível e desejável que elas estejam presentes na rotina escolar. O RCNEI (BRASIL, 1998) indica que as brincadeiras que envolvem o canto, articulado com o movimento, possibilitam a percepção rítmica, a identificação dos segmentos corporais, contato físico e expressividade.

Os resultados sugerem que o movimento impulsiona as atividades, estando presente em todas as dinâmicas observadas. Isso é justificável porque as linguagens da criança se interrelacionam, conforme explicitam os Indicadores de Qualidade da Educação Infantil (BRASIL, 2009), pois, quando a criança se volta para construir conhecimentos, elabora as possibilidades expressivas dos movimentos, ao mesmo tempo em que brinca com as palavras.

Há controvérsia para a permanente utilização dos brinquedos do parque de forma não dirigida. As possibilidades de ações dos brinquedos são limitadas, podendo se esgotar rapidamente se a criança frequenta o mesmo parque durante todo o período pré-escolar. Richter e Vaz (2010, p.65) afirmam que esses brinquedos "dispensam o diálogo, o planejamento, mesmo que provisório, de um espaço comum, pois, para a 'comodidade' dos pequenos, ele já está edificado e 'mobiliado"'. Assim, fornecem indicações a respeito das tarefas, "talvez dificultando as possibilidades de criação de formas diferenciadas de sentir, de pensar, de problematizar e de recriar os movimentos". Há necessidade de intervenção pedagógica também para os espaços do parque.

Situações em que o movimento era o foco central da atividade dirigida foram observadas apenas três vezes (brinquedos de encaixe, atividades com bola e o rastejar). 0 fato de apenas uma sala focar esse segmento, de forma direcionada, pode significar que esse objetivo não é cumprido rotineiramente, indicando uma lacuna na El. A literatura científica indica algumas razões para o não oferecimento dessas atividades: insegurança das professoras generalistas em como abordar o tema (GARANHANI, 2002) ou desconhecimento do tema Movimento (GUIRRA; PRODÓCIMO, 2010).

A recorrência de atividades não dirigidas com brinquedos já conhecidos pelas crianças é comumente encontrada na literatura (BROLO; TOLOCKA, 2010; FARIA; BROLO; TOLOCKA, 2007), o que constata que as crianças de El passam a maior parte do tempo com movimentação restrita, frequentemente aguardando a disponibilidade da equipe pedagógica após os cuidados básicos.

Especificamente com relação às atividades do período matutino, quando há a presença da professora, elas foram diversificadas ea interdisciplinaridade esteve presente. A atividade realizada 
na sala AG I A envolveu uma ligação com o Movimento como finalidade, mais especificamente 0 aperfeiçoamento dos gestos relacionados à preensão (BRASIL, 1998); com as Artes Visuais, com o conhecimento das cores; e com a Linguagem Oral e Escrita, na aquisição de vocabulário. As salas $A G$ I B, AG II A, B e C apresentaram quadro semelhante com o oferecimento de atividades direcionadas e com o incentivo para novas experiências motoras (BRASIL, 2010), por meio de brincadeiras não direcionadas no parque ou no pátio. Todas as turmas realizaram brincadeiras que relacionavam música e movimento, em uma proposta expressiva. Todas essas incidências concordam com os objetivos do RCNEI (BRASIL, 1998) e das DCNEI (BRASIL, 2010).

As atividades da sala AG II D tiveram forte ligação interdisciplinar, pois a partir de um tema fértil (os números), a professora introduziu conceitos com representação gráfica, contagem de pessoas, linguagem oral e movimento.

Durante as atividades do período intermediário, bem como da tarde, as crianças ficam sob a responsabilidade das agentes de educação. Para a ocupação desse cargo, não é exigida formação em nível superior e tampouco formação na área pedagógica, provável razão pela qual não se verificou a realização de atividades que contemplassem os objetivos deste estudo.

Assim, observou-se que, em quatro das cinco salas analisadas, as atividades consistiram em brincadeiras livres em ambientes e com brinquedos conhecidos da criança, com pouca ou nenhuma mediação direta das agentes de educação. Foi possível perceber que elas realizavam atividades já conhecidas e de domínio das crianças. A exceção ocorreu na sala AG II C, na qual uma agente realizou uma atividade interdisciplinar com experiências relacionadas a Movimento, Linguagem Oral e Escrita, Artes Visuais e Natureza e Sociedade.

Ainda com relação às atividades do período vespertino, nas turmas $A G$ I A e B, as crianças foram dirigidas às salas para brincar livremente com os mesmos brinquedos e disposição que em outros períodos do dia, sem que houvesse mediação por parte dos adultos. Ao contrário, na turma AG II D, observou-se que, dentre as atividades relacionadas, houve a oferta de uma cujo foco principal foi estimular o movimento. A atividade teve caráter lúdico e interdisciplinar, envolvendo aspectos dos eixos Natureza e Sociedade.

As atividades do período de espera para a saída das crianças ao final do dia não foram direcionadas pelas educadoras, embora o tempo tenha sido longo (entre 75 e 110 minutos).

Quadro 2 - Locais utilizados para as atividades

\begin{tabular}{|c|c|c|c|c|c|}
\hline & Sala & Parque gramado & $\begin{array}{c}\text { Pátio interno } \\
\text { (Grande) }\end{array}$ & $\begin{array}{c}\text { Pátio interno } \\
\text { (Pequeno) }\end{array}$ & $\begin{array}{c}\text { Parque de } \\
\text { areia }\end{array}$ \\
\hline Acolhimento & $\begin{array}{c}A G \mid A \text { e } B, \\
A G \| B, C \text { e } D\end{array}$ & & $A G \| A$ e $C$ & & \\
\hline Atividades manhã & $A G \| B, C$ e $D$ & $\begin{array}{c}A G \mid A \in B, \\
A G \| C\end{array}$ & $A G \| A$ e $B$ & $A G \| A$ & \\
\hline $\begin{array}{l}\text { Atividades período } \\
\text { intermediário }\end{array}$ & $A G \| C$ & $\begin{array}{c}A G \mid B, A G \| B \\
\text { e D }\end{array}$ & $A G \| A$ & & $A G \mid A$ \\
\hline Atividades tarde & $\begin{array}{c}A G \mid A \in B, \\
A G \| D^{*}\end{array}$ & & & & \\
\hline Saída & $\begin{array}{c}A G \mid A \in B, \\
A G \| A, B, C \text { e }\end{array}$ & & & & \\
\hline
\end{tabular}

Legenda: *As turmas $A G \|$ II $B, C$ e $D$ não mudaram de atividades entre o período intermediário e da tarde. Fonte: Autoria própria.

A maioria das atividades com brincadeiras ocorre em sala. Richter e Vaz (2010) destacam que essa busca por lugares fechados ou restritos do contato com crianças de outras idades busca 
organizar a "dispersão", a "mistura" e a "inabilidade" da infância e esconder os comportamentos que lembram uma natureza não dominada. Essa procura por locais "adequados" coloca-se como uma aliada à produção de sujeitos "higienizados e moralizados" e impede a movimentação irrestrita, livre e de escolha própria de cada criança (WENDHAUSEN, 2012). Destaca-se que, apesar da grande possibilidade de estímulo nas diferentes áreas do desenvolvimento, o tanque de areia foi utilizado apenas uma vez na semana e pelo grupo mais novo.

A seguir, no Quadro 3 (ver na próxima página), serão apresentados os resultados obtidos com o ROBSERV.

A atividade da turma AG I A envolveu não apenas o tema Movimento, como também aspectos relacionados à Natureza e Sociedade e à Linguagem Oral e Escrita. O Movimento, no entanto, foi fundamental para que as crianças pudessem entrar em contato com os demais eixos, pois precisavam deslocar-se até a professora, agarrar objetos e coordenar mãos e olhos para focar os brinquedos manejados pela educadora. Assim, foi incentivada a movimentação das crianças andantes, embora tenha envolvido pouco os bebês.

Com relação à atividade da turma AG I B, destaca-se a brincadeira "estátua", que se alinha ao recomendado pelo RCNEI (BRASIL, 1998), por ser uma brincadeira tradicional que promove o tônus muscular. A atividade de dança com música também é sugerida pelo documento no eixo Música, o qual afirma que, do primeiro ao terceiro ano de vida, as crianças podem explorar gestos sonoros como bater palmas, pernas, pés, correr, pular e movimentar-se de maneira geral, acompanhando sons e melodias de músicas. As demais atividades proporcionaram a escolha de movimentos pelas crianças e foram realizadas em outros espaços da escola. A atividade da sala AG II A, que envolveu as atividades de carrinho e da horta, vem ao encontro das orientações do RCNEI (BRASIL, 1998), no eixo Natureza e Sociedade, que recomenda que as crianças de zero a três anos explorem o ambiente, se relacionem com pessoas e estabeleçam contato com pequenos animais, plantas e objetos diversos para aguçar a curiosidade e promover o movimento.

A atividade da turma $A G \| C$ demonstrou forte estreitamento com os objetivos do Referencial, que indicam a organização de circuitos em espaços internos ou externos sugerindo desafios corporais; a possibilidade de brincadeiras que favoreçam a sensibilidade corporal, como o espirro de água e o vento feito com o colchão; e a disponibilidade de cabanas, túneis e labirintos. Todas as oportunidades criadas nessa atividade relacionaram o Movimento com outros eixos do RCNEl (BRASIL, 1998).

As educadoras responsáveis pela atividade da turma AG II D ilustraram como, a partir do Movimento, as brincadeiras podem envolver todos os eixos do Referencial. A incidência das músicas articuladas com a dança mostrou-se ainda mais significativa por tratar aspectos sociais com as crianças, como trânsito e alimentação. O RCNEI (BRASIL, 1998) indica as danças de roda como uma de suas experiências para o desenvolvimento rítmico, tanto individual como coletivo, a fim de "oferecer a oportunidade de as crianças descobrirem e ajustarem movimentos a ritmos, expressando emoções" (BRASIL, 1998, p. 29). A atividade artística realizada com material reciclável acentua o quanto os temas estão articulados e podem ser explorados de forma interdisciplinar. O ritmo está presente no documento como componente dos eixos Movimento, Matemática, Música e Artes Visuais.

O Quadro 4 (ver na página 1205) ilustra de que forma os diferentes eixos foram tratados nas atividades observadas, enfatizando a importância do Movimento para o desenvolvimento de temas de outras naturezas. 
Quadro 3 - Atividades dirigidas com o tema Movimento

\begin{tabular}{|c|c|c|c|c|c|}
\hline \multirow[t]{2}{*}{ Turma } & \multicolumn{5}{|c|}{ Eixos } \\
\hline & $\begin{array}{l}\text { Número de } \\
\text { crianças }\end{array}$ & $\begin{array}{l}\text { Número de } \\
\text { adultos }\end{array}$ & Tempo e local & Resumo da dinâmica realizada & Reação das crianças à atividade \\
\hline$\frac{\mathbb{Z}}{\mathbb{N}}$ & 19 & $\begin{array}{l}5 \\
\text { (1 professora, } \\
3 \text { agentes e } 1 \\
\text { estagiária) }\end{array}$ & $\begin{array}{l}100 \text { min.; sala de } \\
\text { aula }\end{array}$ & $\begin{array}{l}\text { Atividade com bolinhas de sabão feitas pela professora, enquanto } \\
\text { as crianças tentavam agarrá-las. Brincadeira com catavento, } \\
\text { movimentando-o, assoprando-o ou colocando-o na direção do ventilador } \\
\text { e permitindo que as crianças o tocassem. Interação com os brinquedos } \\
\text { que já estavam no colchão. }\end{array}$ & $\begin{array}{c}\text { As atividades favoreceram apenas a participação das crianças } \\
\text { andantes, permanecendo a maioria dos bebês sem ou com pouco } \\
\text { incentivo à movimentação. }\end{array}$ \\
\hline$\frac{\infty}{\overleftarrow{\leftarrow}}$ & 18 & $\begin{array}{l}4 \\
\text { (1 professora } \\
\text { e } 3 \text { agentes) }\end{array}$ & $\begin{array}{l}50 \text { min.; pátio e } \\
\text { sala de aula }\end{array}$ & $\begin{array}{l}\text { Brincadeira de estátua durante o deslocamento entre sala de aula e } \\
\text { pátio. Brincadeiras na cama elástica, de correr, piscina de bolinha, com } \\
\text { motocas. Na sala de aula, brincadeira de dança com músicas populares } \\
\text { infantis e corrida para buscar objetos. }\end{array}$ & $\begin{array}{l}\text { Desenvolviam as atividades livremente e interagiam entre si, } \\
\text { mesmo com a linguagem verbal ainda pouco desenvolvida. }\end{array}$ \\
\hline 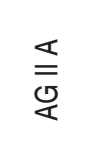 & 13 & $\begin{array}{l}3(1 \\
\text { professora e } \\
2 \text { agentes) }\end{array}$ & $\begin{array}{l}60 \text { min.; sala de } \\
\text { aula, espaço } \\
\text { externo da escola, } \\
\text { horta e parque. }\end{array}$ & $\begin{array}{l}\text { Brincadeira de músicas e dança. Caminhada levando um carrinho feito } \\
\text { de pote de sorvete. Quatro crianças foram levadas para regar a horta. } \\
\text { Brincadeiras livres no parque. }\end{array}$ & $\begin{array}{c}\text { Mostraram-se receptivas às atividades, embora parecessem estar } \\
\text { cansadas das músicas dançadas. A brincadeira do passeio e a ida } \\
\text { à horta mostraram ser motivantes e constituírem novas propostas } \\
\text { de movimentos. }\end{array}$ \\
\hline 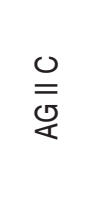 & 10 & $\begin{array}{l}2(1 \\
\text { professora e } \\
1 \text { agente) }\end{array}$ & $\begin{array}{l}40 \text { min.; sala de } \\
\text { aula, com móveis } \\
\text { realocados. }\end{array}$ & $\begin{array}{c}\text { Cantiga de roda. Contação de história com imitação das ações dos } \\
\text { personagens (pedalar, nadar, andar sobre pontes, passar por teias } \\
\text { de aranha, entre outras), com obstáculos compostos pelos móveis } \\
\text { (cadeiras enfileiradas, barbante amarrado às mesas e porta, entre } \\
\text { outros). }\end{array}$ & $\begin{array}{l}\text { Participaram de todas as atividades com interesse e realizando } \\
\text { os desafios motores. Foi incentivada a imaginação, a linguagem } \\
\text { oral com aquisição de vocabulário e as sensações (água borrifada } \\
\text { durante a chuva e colchão abanado para imitar o vento). }\end{array}$ \\
\hline$\stackrel{0}{\stackrel{0}{=}}$ & 19 & $\begin{array}{c}3 \\
\text { (1 professora } \\
\text { e } 2 \text { agentes) }\end{array}$ & $\begin{array}{l}60 \text { min.; sala de } \\
\text { aula }\end{array}$ & $\begin{array}{c}\text { Cantiga de roda. Músicas com brincadeiras e temas (ritmo, alimentação } \\
\text { saudável, cores, o trânsito). Atividades com copos, batendo-os no chão } \\
\text { em ritmo específico, e com tampinhas de potes de requeijão pintadas } \\
\text { em cores diferentes, relacionadas a alimentos que deveriam compor } \\
\text { uma sopa. Utilização do copo para trabalho artístico, carimbando sua } \\
\text { boca no papel com tinta colorida, representando bolhas de sabão. } \\
\text { Brincadeiras com massinha. }\end{array}$ & $\begin{array}{c}\text { Estiveram motivadas no início das atividades e gostaram de cantar } \\
\text { as músicas, continuando-as após o término da ação; porém, em } \\
\text { muitos momentos, foi notado que estavam cansadas e desatentas. } \\
\text { O desempenho das crianças foi positivo e notou-se que, muitas } \\
\text { vezes, elas se ajudaram, de forma a auxiliar o desenvolvimento das } \\
\text { atividades. }\end{array}$ \\
\hline
\end{tabular}


Quadro 4 - Eixos do RCNEI (BRASIL, 1998) envolvidos nas atividades observadas.

\begin{tabular}{|c|c|c|c|c|c|c|}
\hline \multirow[t]{2}{*}{ Turma } & \multicolumn{6}{|c|}{ Eixos } \\
\hline & Movimento & Música & Linguagem Oral e Escrita & Natureza e Sociedade & Matemática & Artes Visuais \\
\hline$\frac{\pi}{\frac{\pi}{c}}$ & $\begin{array}{l}\text { Busca pelas bolinhas de } \\
\text { sabão, aproximação e } \\
\text { manipulação do catavento e } \\
\text { dos brinquedos. }\end{array}$ & - & $\begin{array}{l}\text { Incentivo à verbalização por } \\
\text { meio de diálogos. }\end{array}$ & $\begin{array}{l}\text { Interações com outras } \\
\text { crianças e com educadoras e } \\
\text { divisão de brinquedos. }\end{array}$ & - & $\begin{array}{l}\text { Noções estéticas como } \\
\text { formato, textura, durabilidade, } \\
\text { cores e velocidade dos } \\
\text { brinquedos. }\end{array}$ \\
\hline$\frac{m}{\frac{m}{2}}$ & $\begin{array}{c}\text { Exploração do saltar, } \\
\text { andar, correr, agarrar e } \\
\text { manipulações de objetos. }\end{array}$ & Cantar e ouvir músicas. & $\begin{array}{l}\text { Incentivo à verbalização por } \\
\text { meio de diálogos. }\end{array}$ & $\begin{array}{c}\text { Interações com outras } \\
\text { crianças e com educadoras e } \\
\text { divisão de brinquedos. Início } \\
\text { às brincadeiras com regras } \\
\text { com as corridas. }\end{array}$ & $\begin{array}{l}\text { Atividades rítmicas nas } \\
\text { danças e durante as } \\
\text { caminhadas e contagem para } \\
\text { o início de brincadeiras. }\end{array}$ & - \\
\hline 㐫 & $\begin{array}{l}\text { Movimentos de coordenação } \\
\text { global, articulação de } \\
\text { membros inferiores e } \\
\text { superiores, equilíbrio e } \\
\text { coordenação motora fina. } \\
\text { Conhecimento corporal. }\end{array}$ & Cantar e ouvir músicas. & $\begin{array}{l}\text { Incentivo à verbalização por } \\
\text { meio de diálogos. }\end{array}$ & $\begin{array}{l}\text { Interação entre crianças em } \\
\text { atividades em dupla e com } \\
\text { as educadoras, noções de } \\
\text { responsabilidade e cuidado. } \\
\text { Atividade da horta, com foco } \\
\text { em cuidados da natureza. }\end{array}$ & $\begin{array}{c}\text { Atividades rítmicas com } \\
\text { danças. }\end{array}$ & $\begin{array}{l}\text { Noções estéticas com o } \\
\text { brinquedo confeccionado. }\end{array}$ \\
\hline 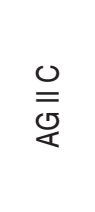 & $\begin{array}{l}\text { Exploração de diferentes } \\
\text { habilidades motoras com } \\
\text { a utilização de objetos/ } \\
\text { obstáculos. }\end{array}$ & $\begin{array}{c}\text { Cantar música para } \\
\text { desenvolver atividades. }\end{array}$ & $\begin{array}{l}\text { Incentivo à verbalização por } \\
\text { meio de diálogos, contação } \\
\text { de história, aquisição de } \\
\text { vocabulário específico. }\end{array}$ & $\begin{array}{l}\text { Interação entre crianças com } \\
\text { atividades em duplas, com } \\
\text { adultos, noções de cuidado e } \\
\text { conhecimento e detalhamento } \\
\text { do ambiente do campo. }\end{array}$ & $\begin{array}{l}\text { Atividades rítmicas com } \\
\text { danças. }\end{array}$ & - \\
\hline$\stackrel{0}{\stackrel{0}{\bar{N}}}$ & $\begin{array}{l}\text { Exploração da coordenação } \\
\text { global, da coordenação } \\
\text { apendicular e da } \\
\text { movimentação facial. }\end{array}$ & $\begin{array}{l}\text { Cantar músicas e trabalho de } \\
\text { rítmica. }\end{array}$ & $\begin{array}{l}\text { Incentivo à verbalização entre } \\
\text { educadoras e crianças. }\end{array}$ & $\begin{array}{l}\text { Interação entre as crianças } \\
\text { em atividades em duplas, } \\
\text { noções de cuidado no } \\
\text { trânsito, alimentação saudável } \\
\text { e utilização ecológica de } \\
\text { objetos em diferentes } \\
\text { brincadeiras. }\end{array}$ & $\begin{array}{c}\text { Atividades rítmicas com } \\
\text { danças e brincadeiras dos } \\
\text { copos. }\end{array}$ & $\begin{array}{c}\text { Ritmo e brincadeira com os } \\
\text { números. }\end{array}$ \\
\hline
\end{tabular}


A ideia de que o Movimento é base para todas as atividades da criança, sendo tanto linguagem como objetivo final de muitas brincadeiras, foi confirmada com a observação realizada. Os dados realçaram que o movimento está presente em todas as atividades e constantemente interligado com outros eixos do conhecimento. Em contrapartida, foi identificada baixa frequência da incidência do Movimento como objetivo central de abordagens pedagógicas.

\section{CONSIDERAÇÕES FINAIS}

Apesar de o RCNEI (BRASIL, 1998) sugerir atividades para o movimento e as DCNEI (BRASIL, 2010) indicarem os caminhos para o desenvolvimento de experiências, algumas educadoras deixaram transparecer que estavam "experimentando" estratégias e apresentavam dificuldades nas interações, principalmente com os bebês.

Mecanismos para transpor essas limitações nas escolas de El são vários, tal como indica a literatura científica: mudança nas possibilidades do ambiente, para torná-lo mais atrativo e desafiador; inserção de novas experiências relacionadas ao movimento, como danças, ginástica e jogos e brincadeiras inseridos em momentos da rotina com intervenções do professor de EF (WENDHAUSEN, 2012); potencialização dos momentos de brincadeiras no parque (BUSSSIMÃO, 2011); e utilização das histórias infantis para a exploração motora (SAYÃO, 2002b). Ayoub (2005) analisou a participação do professor de EF na El, pontuando que a questão principal se concentra na integração entre os diferentes professores e os especialistas para não induzir a ideia de fragmentação e disciplinarização. Por isso, esta pesquisa sugere o viés interdisciplinar na El.

De modo geral, os resultados das atividades práticas indicaram que as professoras se esforçaram para realizar ações que relacionavam o Movimento com todos os eixos do RCNEI (BRASIL, 1998). Ao mesmo tempo, ainda que parcialmente, contemplavam os eixos norteadores do currículo em relação às interações e às brincadeiras constantes das DCNEI (BRASIL, 2010). A presença do elemento lúdico nas atividades também envolveu as crianças, bem como a relação com os aspectos da vida social. Contudo, no período da rotina em que as turmas estavam sob a responsabilidade dos agentes de educação, verificou-se que eles não realizavam, em sua maioria, atividades planejadas com diferentes objetivos ou novas abordagens, possivelmente resultante da não necessidade de formação pedagógica específica para o desenvolvimento dessa função. Da mesma forma, foi identificada a subutilização dos espaços da escola, pois raramente ocorriam mudanças em estruturas frequentemente utilizadas ou mesmo atividades em outros locais fora da sala, embora se ressalte a limitação deste estudo ocasionada pela observação de apenas um dia da rotina de cada turma.

Assim, entende-se que a EF pode contribuir para pensar e estudar o movimento na rotina da El, compondo parcerias em propostas interdisciplinares, que poderiam ser estabelecidas a partir do diálogo sobre práticas pedagógicas, com supervisão do planejamento escolar ou da formação continuada dos profissionais generalistas, favorecendo o desenvolvimento de experiências motoras, articuladas entre si, que incentivem e promovam o desenvolvimento integral da criança pequena. 


\section{REFERÊNCIAS}

AYOUB, Eliana. Narrando experiências com a Educação Física na Educação Infantil. Revista Brasileira de Ciências do Esporte, v. 26, n. 3, p. 143-158, maio 2005.

BASEI, Andréia Paula. A Educação Física na Educação infantil: a importância do movimentar-se e suas contribuições no desenvolvimento da criança. Revista Ibero-Americana de Educação, v. 3, n. 47, p. 1-12, 2008.

BRASIL. Ministério da Educação e do Desporto. Secretaria da Educação Fundamental. Referencial Curricular Nacional para a Educação Infantil. Brasília: MEC/SEF, 1998. Disponível em: <http:// portal.mec.gov.br/seb/arquivos/pdf/volume2.pdf>. Acesso em: 4 ago. 2015.

BRASIL. Qualidade na Educação Infantil. Brasília: MEC/SEB, 2009. Disponível em: <http://portal. mec.gov.br/dmdocuments/indic qualit educ infantil.pdf>. Acesso em: 4 ago. 2015.

BRASIL. Ministério da Educação. Diretrizes Curriculares Nacionais para a Educação Infantil. Resolução CNE/CEB n 5/2009. Brasília, DF: CNE/MEC, 2010. Disponível em: <http://portal.mec.gov. br/index.php?option=com content\&id=12579\%3Aeducacao-infantil\&ltemid=859> Acesso em: 4 ago. 2015.

BROLO, Ana Lucia Ratti; TOLOCKA, Rute Estanislava. Atividades Físicas em instituições de ensino infantil: uma abordagem bioecológica. Revista Brasileira de Cineantropometria \& Desempenho Humano, v. 12, p. 140-147, 2010.

BUSS-SIMÃO, Márcia. Educação Física na Educação Infantil: compartilhando olhares e construindo saberes entre a teoria e a prática. Cadernos de Formação RBCE, v.2, n.1, p. 9-21, jan. 2011.

CERISARA, Ana Beatriz. Educar e cuidar: por onde anda a educação infantil? Perspectiva, v. 17, n. especial, p. 11-21, 1999.

DE MARCO, Ademir. Brincando e aprendendo com a educação física na educação infantil. In: MOREIRA, W. W. et al. (Org.). Ciência do Esporte: Educação, Desempenho e Saúde. Uberaba: UFTM, 2012. p. 83-101.

FALKENBACH, Atos Prinz; DREXSLER, Greice; WERLE, Verônica. Investigando a ação pedagógica da Educação Física na Educação Infantil. Movimento, v. 12, n. 1, p. 81-103, 2006.

FARIA, Maria Catarina Meirelles de; BROLO, Ana Lucia Ratti; TOLOCKA, Rute Estanislava. Análise das oportunidades de lazer no cotidiano infantil in Silva. In: SILVA, Katharine Ninive Pinto; SILVA, Jamerson Antonio de Almeida da. (Org.). Recreação, esporte e lazer espaço, tempo e atitude. Recife: Instituto Tempo Livre, 2007. p. 256-268.

GARANHANI, Marynelma Camargo. A educação física na escolarização da pequena infância. Pensar a Prática, v. 5, p. 106-122, 2001-2002.

GATTÁS, Maria Lúcia Borges; FUREGATO, Antonia Regina Ferreira. Interdisciplinaridade: uma contextualização. Acta Paulista de Enfermagem, v. 19, n. 3, p. 323-327, 2006.

GUIMARÃES, Henrique; POMBO, Olga; LEVY, Teresa. A interdisciplinaridade: reflexão e experiência. Lisboa: Texto, 1994.

GUIRRA, Frederico Jorge Saad; PRODÓCIMO, Elaine. Trabalho corporal na educação infantil: afinal, quem deve realizá-lo? Motriz, v. 16, n. 3, p. 708-713, 2010.

JAPIASSU, Hilton. Interdisciplinaridade e patologia do saber. Rio de Janeiro: Imago, 1976. 
LAKATOS, Eva Maria; MARCONI, Maria de Andrade. Fundamentos de metodologia científica. 5. ed. São Paulo: Atlas, 2003.

NEDEL, Mariana Zamberlan. Educação musical, práticas corporais e interdisciplinaridade: diferentes ferramentas para o processo educativo infantil. Cuadernos de música, artes visuales y artes escénicas, v.5, n. 1, p. 9-30, 2010.

PALOMO, Sandra Maria Silva. Linguagem e linguagens. Eccos Revista Científica, v. 3, n. 2, p. 9-15, 2001.

RICHTER, Ana Cristina; VAZ, Alexandre Fernandez. Educação Física, educação do corpo e pequena infância: interfaces e contradições na rotina de uma creche. Movimento, v. 16, n, 1, p. 53-70, 2010.

SAYÃO, Deborah Thomé. Infância, prática de ensino de Educação Física e Educação Infantil. In: VAZ, Alexandre Fernandez (Org.). Educação do corpo e formação de professores. Reflexões sobre a prática de ensino de Educação Física. Florianópolis: Ed. da UFSC, 2002a. p. 45-95.

SAYÃO, Deborah Thomé T. Corpo e Movimento: Notas para problematizar algumas questões relacionadas à Educação Infantil e à Educação Física. Revista Brasileira de Ciências do Esporte, v. 23, n. 2, p. 55-67, jan. 2002b.

THIESEN, Juares da Silva. A interdisciplinaridade como um movimento articulador no processo ensino-aprendizagem. Revista Brasileira de Educação, v. 13, n. 39, p. 545-554, 2008.

WENDHAUSEN, Adriana Maria Pereira. Conteúdos, linguagens e possibilidades: o relato de uma proposta da Educação Física na Educação Infantil. Cadernos de Formação RBCE, v. 3, n. 2, p. 3145, set. 2012.

\section{Apoio:}

